\title{
Monte Carlo reliability analysis of tophat stiffened composite plate structures under out of plane loading
}

\author{
A.J.Sobey ${ }^{*, a}$, J.I.R.Blake ${ }^{\mathrm{a}}$, R.A.Shenoi ${ }^{\mathrm{a}}$ \\ ${ }^{a}$ Fluid Structure Interactions, University of Southampton, University Rd, Southampton/England, SO17 1BJ
}

\begin{abstract}
Composite materials are often utilised for their high strength to weight ratio, excellent corrosion resistance, etc. but are also characterised by variabilities and uncertainties in their mechanical properties owing to the material make-up, process and fabrication techniques. It is essential that modelling techniques continue to be developed to take account of these variabilities and uncertainties and as more complicated structures are developed it is important to have rapid assessment methods to determine the reliability of these structures. Grillage analysis methods have been previously used for assessment of tophat stiffened composite structures using simple failure criteria. As new criteria are introduced, such as by the World Wide Failure Exercise, the response of more complex topologies must be introduced. This paper therefore assesses the reliability of composite grillages using Navier grillage method incorporating up to date failure criteria. An example, taken from boatbuilding, is used to show the results of using these more complex assessment methods showing that it is of high importance to use the correct assessment criteria.
\end{abstract}

Key words: Monte Carlo Simulation, Composite Failure, Structures

\footnotetext{
${ }^{*}$ Corresponding author

Email address: ajs502@soton.ac.uk (A.J.Sobey)
} 


\section{NOMENCLATURE}

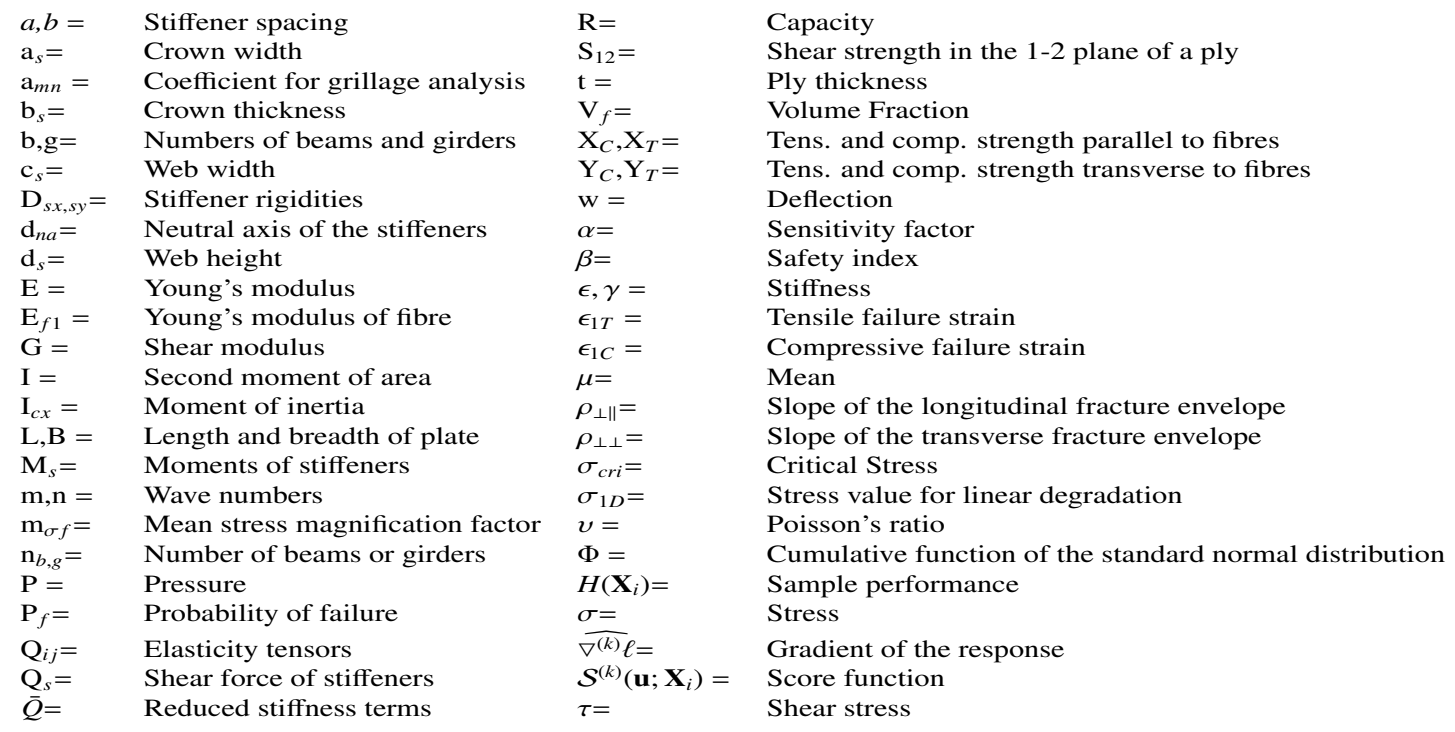

\section{INTRODUCTION}

Composite materials are used within a large number of products for their ability to be created with properties specific to the task required. They exhibit high strength to weight ratio, excellent corrosion resistance and a large design freedom among others. Counter to these benefits composite materials suffer from a relatively low modulus and therefore there is a requirement for stiffeners to be utilised within the structure. Composite structures are often stiffened using a tophat approach which are excellent at providing extra stiffness, at the expense of weight, within the structure an example of this approach can be seen in fig 1.

Currently products used within real life applications are developed using different rules depending on the application of the structure, civil, marine etc.. These rules are typically developed from first principles analysis with the addition of safety factors and/or adjustments made from experience. The adjustments made from past experiences, while ensuring safety, can also lead to structures that are overly conservative leading to a possible increase in emissions. These rules are set in place to ensure that the final structures developed are safe and therefore the rules have been developed with a conservative approach. First principles methods allow the determination of the structural integrity of a product allowing an assessment of the structure predicted without the requirement for safety factors. Analytical methods are a form of first principles approaches that can be used to model structures quickly while retaining a level of accuracy reasonable for structural assessment. Most standards and rules have their origins in these approaches either through the use of reliability or through phenomenological adjustments. These methods also allow a rapid assessment of structures allowing there easy utilisation with stochastic or simulation assessment methods.

Reliability techniques have been in development for a number of years. These methods first appeared in a mathematical form in the 1920's by Mayer [1] and further developed by Streletzki [2] and Wierzbieki [3]. Practical usage of these methods was not developed until the late 1960's with the development of a 


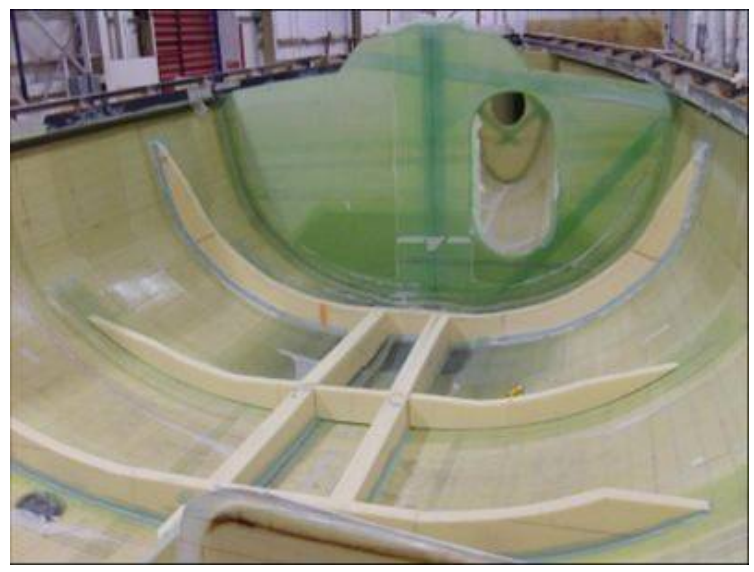

Figure 1: Grillage Stiffened Boat Hull

second-moment reliability index by Cornell [4]. Cassenti [5] furthered deterministic methods by developing the probabilistic static failure analysis procedure of unidirectional laminated composite structures. Yang [6] presented a reliability analysis of laminated plates based on the last-ply-failure analysis concept. Cederbaum [7] presented work related to in-plane loads using first ply-failure on symmetric angle-ply laminates. Thomas [8],[9] developed an analysis result for a single continuous lamina and laminated plate based on weakest link theory and furthered this work by presenting a more precise reliability estimation subjected to multi-axial loads. Kam [10] predicted the reliability of simply supported angle-ply and cantilever symmetric laminated plates subject to large deflections within the context of first-ply-failure. Gurvich [11],[12] developed a probabilistic failure model for the reliability of laminated composites subjected to combined lateral pressure and in-plane loads based on a ply group concept and this was further developed to include both a ply group and a laminated plate subjected to uni-axial tensile loads. Kam [13] developed an analysis procedure for clamped symmetric laminated plates subjected to central point loads based on the first-ply-failure analysis. Mahadevan [14] developed progressive probabilistic progressive failure analysis of laminated plates based on last-ply-failure analysis. Sentler [15] who provided a method for the short and long term stress reliability of composite structures. Boyer et al. [16] performed a reliability analysis of a composite structure to determine appropriate safety factors for composite pipes using three methods: FORM, SORM and Importance Sampling. Miki et al. [17] Investigates the optimum design of multiaxial fiber reinforced laminate systems under probabilistic conditions of loads and material properties. Jeong and Shenoi [18], [19] presented a simulation approach to assess the first-ply failure reliability of composite plates. Chen et al. [20] investigated the reliability of composite top-hat stiffened plates for ship hulls providing a rapid analysis for hull girders. Further work by Chen and Guedes Soares [21] investigated the reliability of ultimate longitudinal strength of composite materials using finite element analysis. Antonio and Hoffbauer [22] who propose a method of uncertainty analysis based on the adjoint variable method. Castillo et al. [23] shows that a sensitivity analysis can be performed in a general optimization problem, including sensitivities of the objective function. Whiteside et al. [24] who show the effects of using a stochastic failure envelope on uni-directionally stiffened carbon/epoxy composites. Eamon and Rais-Rohani [25] performed a reliability analysis on a full composite boat hull as part of a sizing optimisation. An excellent summary and comparison of different reliability studies is given by Sutherland and Guedes Sorares [26]. Guedes Soares [27] also provides a review of different formulations that have been used to assess the reliability of laminates under plane stress 
conditions, assuming that they do not fail by delamination. Chiachio et al. [28] have provided an update of this including the failure criteria chosen for different studies. While these studies have progressed the status of reliability analysis of composite structures the analysis has been performed on simple structures, plates, cylindrical shells and others.

Counter to the many benefits composite materials exhibit they also suffer from a relatively low modulus and therefore there is a requirement for stiffeners to be utilised within the structure. Composite structures are often stiffened using a tophat approach, an example of which is shown in Figure 2 which provide necessary flexural and axial stiffness, to the structure.

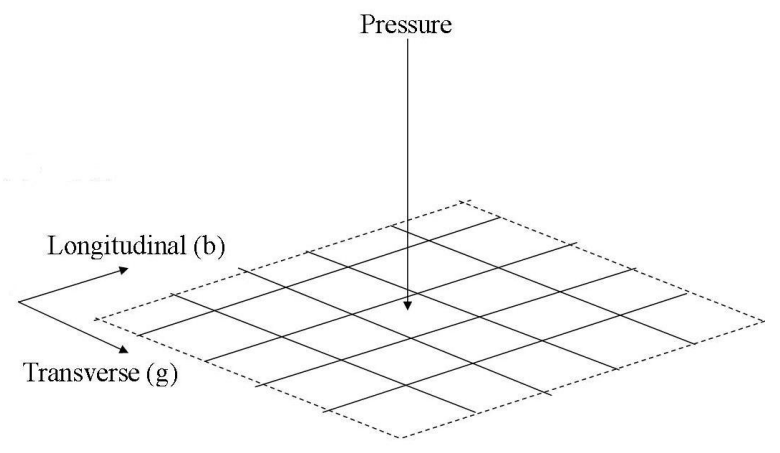

Figure 2: Grillage Stiffened Plate in a Boat Structure

An analysis of these more complex structures must be performed before they are utilised within a product. Previous analysis has looked at the development of grillage analysis as a method for rapidly analysing the structures allowing the use of Monte Carlo methods for use within growing more complex reliability assessments. Blake et al. [29] looked at a method for assessing the reliability of composite grillages ustilising Navier grillage theory with simple limit states. This research showed that grillage theory was good for assessing more complex composite structures however stringent limit states are required for a more realisitic analysis.

There is a large quantity of literature relating reliability to simple composite structures. Limited work has been carried out into the reliability assessment of composite grillages. While composite structures and tophat stiffened structures have been investigated these studies have been developed with limit states based on maximum stress and deflection failure criteria. This previous work has shown that the choice of failure criteria is of key importance and for the analysis of first principles composite plates that more substantial failure criteria must be utilised. While it can be seen that the incorporation of spatial reliability and the stochastic nature of the materials relating to the failure criteria are important these are not incorporated due to low volumes of data. This paper therefore aims to investigate the probability of failure for tophat stiffened grillages using failure criteria developed from the world wide failure exercise. This paper looks at a grillage analysis of composite tophat stiffened plate structures, taken from boatbuilding as an example, using Monte Carlo simulations to analyse different composite materials. The paper analyses the differences in reliability between e-glass/vinylester and carbon/epoxy composite materials using a Navier grillage analysis. This model incorporates failure criteria based on strength and stiffness parameters to assess the reliability of the plates. 


\section{STRUCTURAL MODEL}

\subsection{Introduction}

For the structural modelling of the stiffened plate Navier method grillage analysis has been adopted. This work is originally covered in Vedeler [30] and the has been shown in Maneepan et al. [31] to closely approximate the exact answer while being computationally more efficient. Navier theory is based upon the deflection of intersecting points found between longitudinal girders and transverse beams as shown in Fig. 2 with the direction of pressure shown. From these deflections it is possible to determine the stresses within the stiffeners. This method has been used for many years and is combined with elastic stress analysis as covered in Datoo [32]. The grillage analysis uses the Navier summations of points within the grillage to develop the deflection of the stiffeners. This methodology has been performed based on a plate under simply supported boundary conditions. The equation giving deflection of the stiffened plate is assumed to be

$$
w(x, y)=\sum_{m=1}^{\infty} \sum_{n=1}^{\infty} a_{m n} \sin \frac{m \pi x}{L} \sin \frac{n \pi y}{B}
$$

where the value of $\mathrm{a}_{m n}$ is a coefficient found from Eq.4. The coefficient $\mathrm{a}_{m n}$ is found based on the assumption that the change in potential energy from the deflection will be a minimum. From the deflection curve of the $\mathrm{q}^{\text {th }}$ beam and $\mathrm{p}^{\text {th }}$ girder, where $\mathrm{x}$ is a constant $\mathrm{x}_{q}=q L /(b+1)$ or $\mathrm{y}_{p}=p B /(g+1)$ is a constant to investigate the deflections along the specified beam, it is possible to show the strain energy, $\mathrm{V}$ :

$$
V=\int_{0}^{L} \frac{D_{g}}{2}\left(\frac{\partial^{2} w}{\partial x^{2}}\right)_{y=y_{p}}^{2} d x+\int_{0}^{B} \frac{D_{b}}{2}\left(\frac{\partial^{2} w}{\partial y^{2}}\right)_{x=x_{q}}^{2} d y
$$

The work done on the grillage can be shown to be:

$$
\int_{0}^{L} \int_{0}^{B} P \sum_{m=1}^{\infty} \sum_{n=1}^{\infty} a_{m n} \sin \frac{m \pi x}{L} \sin \frac{n \pi y}{B} d x d y
$$

Minimising the potential energy $\left(\partial \mathrm{V} / \partial \mathrm{a}_{m n}\right)$ and equating it to the work done it is then possible to find $\mathrm{a}_{m n}$ in Eq.4. The coefficient $\mathrm{a}_{m n}$ is dependent on the flexural rigidities of the stiffeners $\left(\mathrm{D}_{g, b}\right)$.

$$
a_{m n}=\frac{16 P L B}{\pi^{6} m n\left\{m^{4}(g+1) \frac{D_{g}}{L^{3}}+n^{4}(b+1) \frac{D_{b}}{B^{3}}\right\}}
$$

The moments can be found in the beams or girders $\left(\mathrm{M}_{g, b}\right)$ from Eq.5:

$$
M_{g, b}=-D_{g, b} \frac{\partial^{2} w}{\partial x^{2}}
$$

Finally using the maximum moments in the grillage the maximum stress $\sigma_{\max }$ can be determined, where $\mathrm{E}_{s(i)}$ is the Young's modulus of the element of a stiffener, either girder or beam, $\mathrm{M}_{s}$ is the moment created in the stiffener, $\mathrm{Z}_{s}$ is the vertical distance of the centroid of an element to the neutral axis and $\mathrm{D}_{s}$ is the structural rigidity of a stiffener:

$$
\sigma_{\max }=\frac{E_{s(i)} M_{s} Z_{s}}{D_{s}}
$$




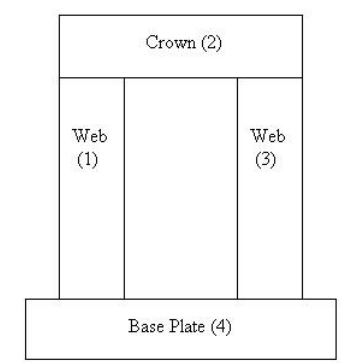

Figure 3: Stiffener element names and numbers

The tophat stiffeners are idealised as shown in Figure 3 with each stiffener being made up of 4 elements labelled 1 to 4 . Each of these elements is made up of a number of different plies.

A grillage panel is then constructed of a number of these stiffeners on top of a flat plate. The flexural rigidity can be found using these elastic equivalent properties method which can be found in Datoo [32]. The flexural rigidity can then be used to determine the stresses in the stiffeners using the Navier grillage method.

\subsection{Failure Criteria}

Further to previous work reported by Sobey [33] the failure criteria used came from the 'World Wide Failure Exercise' (WWFE) [34], [35] and [36]. The choice made for each failure type can be seen from Table 1. In the cases where a choice could be made between a conservative and unconservative estimate it has been decided to use a conservative estimate. Different methods have been compared by Soden [37].

\begin{tabular}{|l|c|}
\multicolumn{2}{|c|}{ Table 1: Failure Criteria } \\
\hline Failure Type & Criteria \\
\hline $\begin{array}{l}\text { Predicting the } \\
\text { response of lamina }\end{array}$ & Puck [38], [39] and Tsai [40], [41] \\
\hline $\begin{array}{l}\text { Predicting final strength } \\
\text { of multidirectional laminates }\end{array}$ & Puck [38], [39] \\
\hline $\begin{array}{l}\text { Predicting the } \\
\text { deformation of laminates }\end{array}$ & Zinoviev [42], [43] and Puck [38], [39] \\
\hline
\end{tabular}

Furthermore an arbitrary deflection limit of $1 \%$ of the length has been included to ensure that materials with a low stiffness and cost cannot be selected without creating a thicker topology. A brief desciption follows but for further explanation of these differing criteria the references listed can be used.

\subsubsection{Puck Failure Criteria}

TThe Puck failure criteria is based upon 3-D phenomenological models where the development of the method is done through matching current theory to experimental results. The Puck method is recommended by the World Wide Failure Exercise to be used for predicting strength of unidirectional laminae and this method has been used as it gives a more conservative view for the failure of the laminates. Puck's formulation is also used for predicting the initial strength of multidirectional laminates as other methods did not predict the failure very well. Puck is further recommended to be used to predict final strength of multidirectional laminates. 
Table 2: Puck failure criteria

\begin{tabular}{|l|c|}
\hline Table 2: Puck failure criteria \\
\begin{tabular}{|l|c|}
\hline Fibre failure in tension & $\frac{1}{\epsilon_{1 T}}\left(\epsilon_{1}+\frac{v_{f 12}}{E_{f 1}} m_{\sigma f} \sigma_{2}\right)=1$ \\
\hline Fibre failure in compression & $\frac{1}{\epsilon_{1 C}}\left[\left(\epsilon_{1}+\frac{v_{f 12}}{E_{f 1}} m_{\sigma f} \sigma_{2}\right) \mid=1-\left(10 \gamma_{21}\right)^{2}\right.$ \\
\hline $\begin{array}{l}\text { Inter-fibre failure mode A } \\
\text { for transverse tension) }\end{array}$ & $\sqrt{\left(\frac{\tau_{12}}{S_{12}}\right)^{2}+\left(\rho_{\perp \|}^{(+)} \frac{Y_{T}}{S_{21}}\right)^{2}+\left(\frac{\sigma_{2}}{Y_{T}}\right)^{2}}+\rho_{\perp \|}^{(+)} \frac{\sigma_{2}}{S_{12}}=1-\frac{\sigma_{1}}{\sigma_{1 D}}$ \\
\hline $\begin{array}{l}\text { Inter-fibre failure mode B } \\
\text { (for moderate transverse compression) }\end{array}$ & $\frac{1}{S_{21}}\left(\sqrt{\tau_{21}^{2}+\left(\rho_{\perp \|}^{(-)} \sigma_{2}\right)^{2}}\right)+\rho_{\perp \|}^{(-)} \sigma_{2}=1-\frac{\sigma_{1}}{\sigma_{1 D}}$ \\
\hline $\begin{array}{l}\text { Inter-fibre failure mode C } \\
\text { (for large transverse tension) }\end{array}$ & {$\left[\left(\frac{\tau_{21}}{2\left(1+\rho_{\perp \perp}^{(-)}\right) S_{21}}\right)^{2}+\left(\frac{\sigma_{2}}{Y_{C}}\right)^{2}\right] \frac{Y_{C}}{\left(-\sigma_{2}\right)}=1-\frac{\sigma_{1}}{\sigma_{1 D}}$} \\
\hline
\end{tabular}
\end{tabular}

\subsubsection{Zinoviev Failure Criteria}

The Zinoviev failure criteria is based on the development of maximum stress theory. This method is based on composite laminate theory and has a linear solution. Zinoviev is recommended by the World Wide Failure Exercise to predict the deformation of laminates along with a non-linear method such as Puck.

Table 3: Zinoviev failure criteria
\begin{tabular}{|l|c|}
\hline Longitudinal tension failure & $\sigma_{1}=X_{T}$ \\
\hline Longitudinal compressive failure & $\sigma_{1}=X_{C}$ \\
\hline Transverse tensile failure & $\sigma_{2}=Y_{T}$ \\
\hline Transverse compressive failure & $\sigma_{2}=X_{C}$ \\
\hline In-plane shear failure & $\tau_{12}=S_{12}$ \\
\hline
\end{tabular}

\subsubsection{Tsai Failure Criteria}

The Tsai failure criterion is developed through an interactive progressive quadratic failure criterion. This method is also based on composite laminate theory and is linear in its solution. The Tsai failure criterion are used in conjunction with Puck to determine the response of lamina. The Tsai failure criterion is the best fit to the test data reported in Soden [37] for the behaviour of the laminates. This criterion underestimates the failure stress at given points and so the Puck failure criterion can be used to check that failure does not occur.

$$
\left(\frac{\sigma_{1}}{X_{T} X_{C}}\right)^{2}+\left(\frac{\sigma_{2}}{Y_{T} Y_{C}}\right)^{2}+\left(\frac{1}{X_{T}}-\frac{1}{X_{C}}\right) \sigma_{1}+\left(\frac{1}{Y_{T}}-\frac{1}{Y_{C}}\right) \sigma_{2}+\left(\frac{2 F_{1} 2 \sigma_{1} \sigma_{2}}{\sqrt{X_{T} X_{C} Y_{T} Y_{C}}}\right)+\left(\frac{\tau_{12}}{S_{12}}\right)^{2}=1
$$

\section{THE RELIABILITY APPROACH}

\subsection{Monte Carlo Methods}

A Monte Carlo simulation method has been chosen for the prediction of the reliability of composites as this technique will allow an ability to easily make changes to the models and to allow systems reliability and covariance to be added in future models. The Monte Carlo method has three main steps: 
1. Generate a randomly distributed set of input variables.

2. Perform calculations based on the set of input variables.

3. Determine probability from a large number of repetitions.

A number of simulations were run for each set of statistical distributions resulting in a given reliability for that product and the production technique used. The number of simulations can be calculated from Nowak and Collins [44]:

$$
N=\frac{1-P_{\text {true }}}{V_{\bar{P}}^{2}\left(P_{\text {true }}\right)}
$$

where $\mathrm{N}$ is the number of runs, $P_{\text {true }}$ is the theoretically correct probability, and $V_{\bar{P}}^{2}$ is the coefficient of variation of the estimate. For a high accuracy, orders of magnitude more simulations than the reciprocal of the magnitude of the probability being determined must be used. For this situation it is possible to estimate the correct probability of failure from that of Blake et al. [45], determined using Second-Order Reliability Methods, and, using an accuracy of $10 \%$, indicating that approximately $10^{8}$ generations will be required.

Having determined the statistical input variables for each simulation it is then possible to determine the outputs. In this case outputs are deflection, failure criteria, mean cost or maximum stress from the model being used i.e. the grillage. These outputs can be compared to the limit state. The general limit state function is given by eq. 9 :

$$
g(R, Q)=R-Q
$$

where $\mathrm{R}$ is the capacity $\mathrm{Q}$ is the demand. For the determination of a specific reliability it is important to determine the limit states that bound the characteristics of interest e.g. maximum stress. The performance function for the limit state is given as:

$$
P_{f}=P(R-Q<0)=P(g<0)
$$

where $P_{f}$ is the probability of failure, which is the probability of the demand being larger than the capacity and in this case is the probability that the panel will not be able to cope with the pressure load that it is subjected to.

The reliability is dependant upon the statistical distributions of the inputs. Different inputs are generally grouped together with statistical distributions as determined by structural codes e.g. CIRIA [46], DNV [47] or EUROCOMP [48]. Pressure and material definitions are typically of a Weibull and Normal nature respectively, as can be seen from Table 4 given by the DNV design rules [47].

Table 4: Typical Distributions for Input Variables

\begin{tabular}{cc}
\hline Variable & Distribution Type \\
\hline Current - Long Term Speed (Pressure) & Weibull \\
Properties - Yield Strength (Steel) & Normal \\
Properties - Young's Modulus & Normal \\
Properties - Initial Deformation of Panels & Normal \\
\hline
\end{tabular}

Having generated a random number for the input variables these values can then be used in the structural model. After this processing it will be possible to determine the reliability of the panel and the sensitivity 
of the structure to each input variable. The sensitivity can aid the understanding of different structures and scenarios. This is achieved by determining how different variables relate to one another and the level of influence variables have on the probability of failure. This can be undertaken using a sensitivity index defined in Rubinstein [49]:

$$
\widehat{\nabla^{(k)}} \ell(\mathbf{u})=\frac{1}{N} \sum_{i=1}^{N} H\left(\mathbf{X}_{i}\right) \mathcal{S}^{(k)}\left(\mathbf{u} ; \mathbf{X}_{i}\right)
$$

where $\widehat{\nabla^{(k)}} \ell(\mathbf{u})$ is the gradient of the response, $H\left(\mathbf{X}_{i}\right)$ is the sample performance and $\mathcal{S}^{(k)}\left(\mathbf{u} ; \mathbf{X}_{i}\right)$ is the score function. The gradient can be found from the score functions of each distribution defined in Rubinstein [49] and shown in eq. 12, for the Normal distribution, and in eq. 13, for the Weibull distribution.

$$
\begin{aligned}
& \mathcal{S}(\mathbf{u} ; x)=\left(\sigma^{-2}(x-\mu),-\sigma^{-1}+\sigma^{-3}(x-\mu)^{2}\right) \\
& \mathcal{S}(\mathbf{u} ; x)=\left(\alpha-1+\ln (\beta x)\left[1-(\beta x)^{\alpha}\right], \frac{\alpha}{\beta}\left[1-(\beta x)^{\alpha}\right]\right)
\end{aligned}
$$

These sensitivity numbers relate the effect that the input characteristics have upon the output. These values are the gradients and therefore the larger their values the higher the effect the input has on the output reliability index.

It is possible to see the variables that would need varying from Eq. 14 and Eq. 15. The total runs of the random number generator is therefore the number of runs $\mathrm{N}$ multiplied by the variables, 9 for the results given in Table 8 .

$$
\begin{aligned}
x_{\text {stress }}= & X_{t}\left(E_{f}, E_{m}, V_{f}, \epsilon_{f}^{*}\right) \\
& -\sigma_{\max }\left(L, B, P, E_{f}, E_{m}, G_{F}, G_{m}, V_{f}\right) \\
x_{\text {deflection }=} & k \times w_{\max } \\
& -w\left(L, B, P, E_{f}, E_{m}, G_{F}, G_{m}, V_{f}\right) \\
\sigma_{\text {failure }}= & C r i t_{F a i l}\left(E_{f}, E_{r}, V_{f}, \epsilon_{f}^{*}, \epsilon_{r}^{*}\right) \\
& -\left(\sigma_{\text {max }}\left(L, B, P, E_{f}, E_{r}, G_{F}, G_{r}, V_{f}\right)+\tau\left(L, B, P, E_{f}, E_{r}, G_{F}, G_{r}, V_{f}\right)\right. \\
& +w\left(L, B, P, E_{f}, E_{r}, G_{F}, G_{r}, V_{f}\right)
\end{aligned}
$$

Having considered the variables through the structural model it is then possible to determine whether a given set of variables leads to a safe structure or not. Validation of the Monte Carlo method was carried out for the stress limit state, Eq. 14, the deflection limit state, Eq. 15 and the WWFE limit state, Eq. 16. In the results tables shown below for the deflection limit state it is assumed that the value of $\mathrm{k}=2$ implying that the deflection of the panel must reach higher than 2 times the deflection produced using the mean results. For the stress limit state the tensile strength is calculated for each plate using Eq. 17.

$$
X_{t}=\left(E_{f} V_{f}+E_{m} V_{m}\right) \epsilon_{1 T}
$$


The total number of failed panels can then be assessed. The code is run for a number of panels, N, the number of panels that fail are then compared to the total which is therefore the probability of failure and from there the reliability index can be found.

\section{RESULTS}

\subsection{Validation of structural model}

Validation of the first principles structural analysis method was carried out to ensure that elastic stress theory would create reasonable results with grillage analysis. The results from the grillage method have been compared to the more computationally expensive but more accurate displacement method found in Clarkson [50] for a plate with a length and width of $3180 \mathrm{~mm}$. The plate consisted of 4 beams and girders with dimensions $254 \mathrm{~mm}$ deep $127 \mathrm{~mm}$ wide with $18.288 \mathrm{~mm}$ thick flanges and $9.144 \mathrm{~mm}$ thick webs and a pressure of $137.9 \mathrm{kPa}$ was applied to each plate. This analysis allows an assessment of the plate under simply supported conditions. The results are presented in Tab. 5.

\begin{tabular}{ccc}
\multicolumn{3}{c}{ Table 5: Validation of Navier method grillage analysis } \\
\hline Property & Clarkson & Grillage Model \\
\hline Deflection & $9.63 \mathrm{~mm}$ & $9.87 \mathrm{~mm}$ \\
Stress & $165.52 \mathrm{MPa}$ & $170.13 \mathrm{MPa}$ \\
\hline
\end{tabular}

These values were found to be close to the previous results as can be seen in Tab. 5 and therefore the grillage method was used for the stiffener modeling. The elastic equivalent properties were compared to Datoo [32] using lamina properties $E_{1}=140 \mathrm{kN} / \mathrm{mm}^{2}, \mathrm{E}_{2}=10 \mathrm{kN} / \mathrm{mm}^{2}, \mathrm{G}_{12}=5 \mathrm{kN} / \mathrm{mm}^{2}, v_{12}=0.3$ and a ply thickness $=0.125 \mathrm{~mm}$ for each of the 8 plies all having a $0^{\circ}$ ply angle where the result was identical to Datoo's value of $140 \mathrm{GPa}$.

\subsection{Monte Carlo Simulation}

\subsubsection{Verification}

Validation of the Monte Carlo simulation that is being used for the reliability studies was determined by comparison with work previously carried out on a composite grillage plate. This work used the same grillage as Clarkson [50] given previously. To determine the reliability of the plate it is assumed to have characteristics as shown in Tab. 6 these properties have been taken from Shenoi et al. [51] where the distributions are orginally based on information found in the DNV rules [52].

Where normal distribution has been shown this represents a truncated normal distribution to ensure that negative results could not be introduced. While it can be seen that the Monte Carlo Simulation was working correctly a convergence analysis was performed. This is shown in table 7.

It is then possible to compare the reliability from Monte Carlo into those from FORM/SORM of Shenoi et al. [51] Tab. 8.

From these results it can be seen that it is possible to get a good degree of accuracy to the results that have been presented with the Monte Carlo simulation running to $5.5 \%$ of the probability of failure for the FORM results. Compared to the SORM results the Monte Carlo simulation produced results $42.5 \%$ of the probability of failure. This shows the method could be used for the analysis of the structurally optimised plate.

Having determined the probability of failure for the two materials the Monte Carlo methods it was then possible to determine the sensitivity of the output to each of the inputs. In terms of the structural model these 
Table 6: Panel Characteristics - Verification

\begin{tabular}{|c|c|c|c|c|c|}
\hline & \multicolumn{2}{|c|}{ carbon/epoxy } & \multicolumn{2}{c|}{ e-glass/vinylester } & \\
\hline Material & Mean & CoV $\%$ & Mean & CoV \% & Distribution \\
\hline Length & $3810 \mathrm{~mm}$ & 3 & $3810 \mathrm{~mm}$ & 3 & Normal \\
\hline Breadth & $3810 \mathrm{~mm}$ & 3 & $3810 \mathrm{~mm}$ & 3 & Normal \\
\hline Pressure & $137 \mathrm{kPa}$ & 15 & $137 \mathrm{kPa}$ & 15 & Weibull \\
\hline$E_{f}$ & $826 \mathrm{GPa}$ & 5 & $71 \mathrm{GPa}$ & 3 & Normal \\
\hline$E_{m}$ & $3 \mathrm{GPa}$ & 3 & $3.4 \mathrm{GPa}$ & 3 & Normal \\
\hline$G_{f}$ & $41.3 \mathrm{GPa}$ & 3 & $35.5 \mathrm{GPa}$ & 3 & Normal \\
\hline$G_{m}$ & $1.09 \mathrm{GPa}$ & 3 & $1.13 \mathrm{GPa}$ & 3 & Normal \\
\hline$V_{f}$ & 0.6 & 3 & 0.55 & 3 & Normal \\
\hline$\epsilon_{f}$ & 0.3 & 3 & 3 & 3 & Normal \\
\hline
\end{tabular}

Table 7: Verification of Monte Carlo Simulation

\begin{tabular}{ccc}
\hline Runs & Failures & Probability of Failure \\
\hline $10^{1}$ & 0 & 0 \\
$10^{2}$ & 0 & 0 \\
$10^{3}$ & 0 & 0 \\
$10^{4}$ & 0 & 0 \\
$10^{5}$ & 0 & 0 \\
$10^{6}$ & 1 & $1 \times 10^{-6}$ \\
$10^{7}$ & 18 & $1.8 \times 10^{-6}$ \\
$10^{8}$ & 146 & $1.46 \times 10^{-6}$ \\
$4.44 \times 10^{8}$ & 675 & $1.53 \times 10^{-6}$ \\
$10^{9}$ & 1490 & $1.49 \times 10^{-6}$ \\
\hline
\end{tabular}

results are shown in fig. 4 for the case of the carbon/epoxy panel and fig. 5 for the e-glass/vinylester test case. These results show that the stress limit state is not affected by the material properties. This is because the stresses are in the region of $170 \mathrm{MPa}$ for the average panel with a failure of $1470 \mathrm{MPa}$ in the case of the carbon/epoxy and $887.5 \mathrm{MPa}$ e-glass/vinylester. The results for the stress have therefore been discounted. For the results shown in Table 4 and 5 each of the gradients has been normalised using the average value for the characteristic. Using these normalised values it is possible to compare these values to each other in terms of effect on the deflection. The mean deflection for the carbon/epoxy panels was $41.19 \mathrm{~mm}$ and for the e-glass/vinylester this value was $552.52 \mathrm{~mm}$. The results shown in 4 have been compared to Shenoi et al. [51] and have a fair comparison. In both of the scenarios, carbon/epoxy and e-glass/vinylester, the stress limit state has not been broken. This indicates that for both of the failures it is a deflection dependant failure. This shows that the plate itself was designed well to withstand the predicted stress. Furthermore it can be seen that the sensitivity analysis for the Monte Carlo simulation, while not identical to those produced using FORM/SORM methodologies, show an acceptable level of similarity to use this methodology as a method for determining the sensitivity of the different variables. 
Table 8: Comparison of FORM/SORM and Monte Carlo Reliability

\begin{tabular}{ccc}
\hline Method & $\begin{array}{c}\text { Probability of Failure } \\
P_{f}\left(10^{-6}\right)\end{array}$ & $\%$ Error compared to SORM \\
\hline FORM [51] & 1.384 & $32.4 \%$ \\
SORM [51] & 1.045 & $0 \%$ \\
Monte Carlo & 1.49 & $42.5 \%$ \\
\hline
\end{tabular}

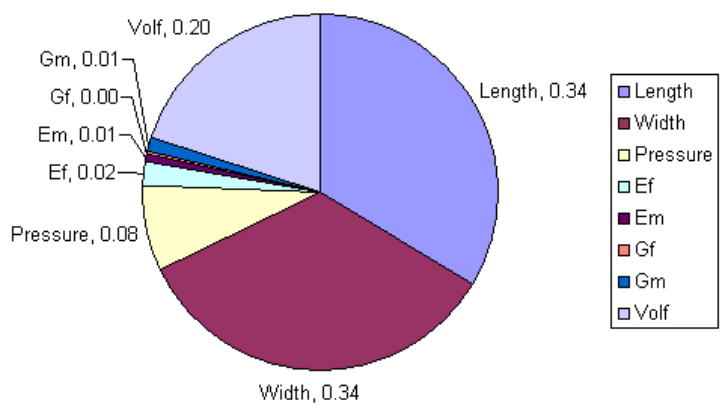

Figure 4: Sensitivity of deflection to inputs - carbon/epoxy

The initial probability of failure for the carbon/epoxy material, $1.49 \times 10^{-6}$, was a reasonable level of failure for a carbon/epoxy material giving a low probability of failure compared to other structures developed for similar applications [53]. For the e-glass/vinylester material the probability of failure was $8.6 \times 10^{-7}$. This shows that for the dimensions that have been used that the e-glass plate was less likely to fail than the carbon/epoxy panel, an unlikely scenario due to carbon's superior material properties. It is therefore likely that the failure criteria that are being used are not acceptable. Therefore for future comparisons between the two materials it will be important to develop a more stringent set of limit states based on a rigid deflection limit state. This can be seen when a comparison between the different deflections is made with the carbon/epoxy panel having a deflection over 13 times smaller.

For the case of the carbon/epoxy plates it can be seen that the failure was most dependant upon the length and width over which the stiffener spacing was used. The next most important value was that of the volume fraction of fibre within the grillage. For the e-glass/vinylester plate it can be seen that the sensitivity was mainly dependant upon the properties of the material in the plate combined with the volume fraction of the fibres. The difference in these levels can be explained by the variation in the volume fraction of fibre that might be seen in the fibre. Due to e-glass having a high variation in the fraction of fibres in the plate the material properties became more important in the analysis. The carbon plate however had less variation and therefore the dimensions over which the plate would be used were more important.

\subsubsection{World Wide Failure Exercise Analysis}

Finally an analysis has been performed on the same grillage plate using the WWFE criteria and a maximum deflection criteria of $1 \%$. The properties that have been used are the same as shown in Table 6 except 


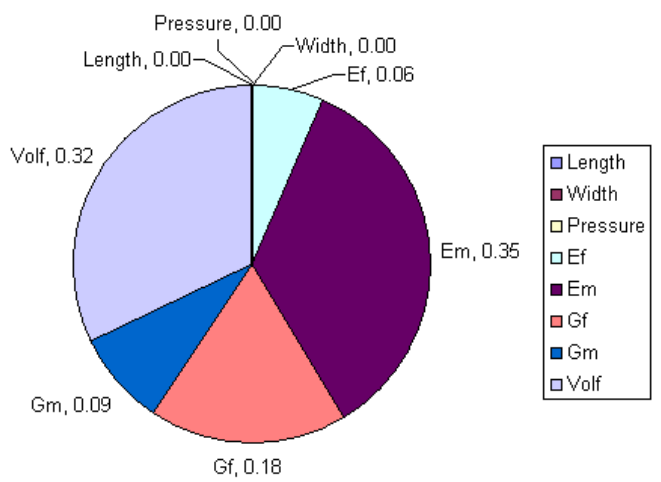

Figure 5: Sensitivity of deflection to inputs - e-glass/vinylester

Table 9: Comparison of probability of failure

\begin{tabular}{ccc}
\hline & carbon/epoxy & e-glass/vinylester \\
\hline Probability of failure & $6 \times 10^{-4}$ & $3 \times 10^{-2}$ \\
Normalised Compared to Mass (Pf/kg) & $1.07 \times 10^{-6}$ & $4.19 \times 10^{-5}$ \\
Normalised Compared to Cost (Pf/pounds) & $1.77 \times 10^{-7}$ & $1.1 \times 10^{-5}$ \\
\hline
\end{tabular}

that a lower value of 286GPa for the Young's Modulus of the carbon has been used as it was felt this was a more realistic value for this property.

Having determined the different materials properties it was then possible to evaluate the probability of failure of the two panels with the WWFE criteria. The probabilities of failure for the carbon/epoxy plate were $6 \times 10^{-4}$ and $3 \times 10^{-2}$ for the e-glass/vinylester plate. These values can be normalised to the cost and mass, shown in table 9 of the panels where the cost and mass of the carbon/epoxy plate were $£ 3389$ and 559 $\mathrm{kg}$ and the cost and mass of the e-glass/vinylester plate were $£ 2722$ and $715 \mathrm{~kg}$

Having determined the probability of failure for the two materials using the Monte Carlo methods it was then possible to determine the sensitivity of the reliability output to each of the inputs. In terms of the structural model these results are shown in fig. 6 for the case of the carbon/epoxy panel and fig. 7 for the e-glass/vinylester test case.

It can be seen from these results of the probability of failure that the plate constructed using the eglass/vinylester material was likely to fail. For the carbon/epoxy plate the probability of failure shows that the plate was less likely to fail. This probability of failure, though still high, falls closer to the probability of failure of products that are constructed in the real world. The probabilities of failure for these plates are much higher than those produced in the previous study Shenoi et al. [51]. From normalising the probabilities of failure for the plate for cost, even though the carbon still outperforms the e-glass/vinylester, that the results show a closer performance. This is as expected where the e-glass/vinylester is cheaper but heavier and a less strong and stiff material. The sensitivity analysis shows a large difference in the sensitivity of failure to the different input variables between the previous study and the new one. The e-glass/vinylester plates showed a significant dependency on a number of different factors: predominantly the dimensions over which the stiffener spacings were used and the pressure that was applied to the plate. The carbon plate was shown to 


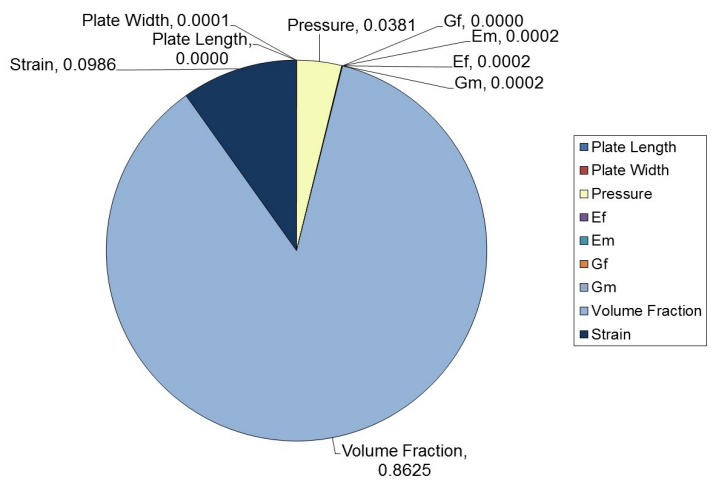

Figure 6: Sensitivity of stress to inputs - carbon/epoxy

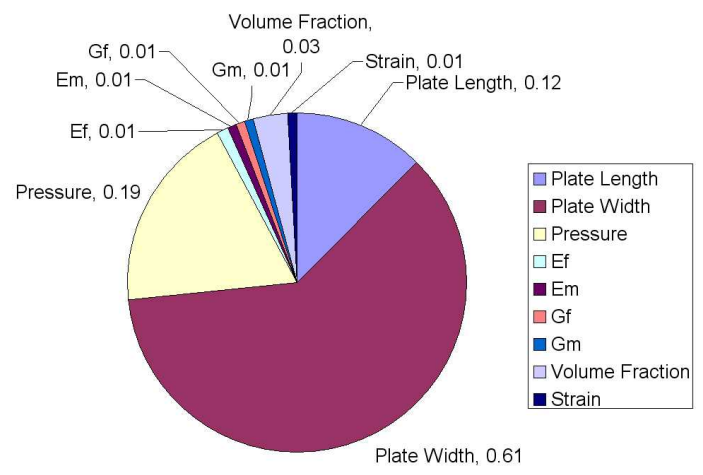

Figure 7: Sensitivity of stress to inputs - e-glass/vinylester

be mainly affected by the volume fraction, failure strain and pressure.

\section{Discussion}

It can be seen that for the WWFE analysis the e-glass/vinylester plate has a much higher probability of failure than that of the carbon/epoxy one. The mean masses for the two panels were determined to be $16.22 \mathrm{~kg}$ for the carbon/epoxy and $14.2 \mathrm{~kg}$ for the e-glass/vinylester. This shows a small variation in the mass between the two plates however the difference in probability of failure between them was much larger at 50 times more likely for the eglass/vinylester plate to fail. The introduction of the WWFE and a maximum deflection criteria introduced more realistic figures for the probability of failure for the plates increasing the probability of failure from $1.49 \times 10^{-6}$ for the carbon/epoxy and $8.6 \times 10^{-7}$ for the e-glass/vinylester to $6 \times 10^{-4}$ and $3 \times 10^{-2}$ respectively. The results show that for the first analysis that the e-glass/vinylester plate is more likely to fail than that of the carbon/epoxy these results are unrealistic. This is rectified in the second analysis showing that e-glass/vinylester could not be used in this application. All of the results that have been produced show a large dependence upon the material properties especially the Young's Modulus of the fibre. This result is expected as the failure criteria are dependant on these values as does the deflection of the plate. 
The plate analysis from previous work result in an ultimate stress limit state which is never violated and therefore world wide failure exercise criteria have been introduced to evaluate the plate. The deflection limit state is created by using $\mathrm{k}, 2$, times the mean value for the deflection in each situation. This means that the deflection limit state is dependant upon the plate being analysed and not a standard value. This indicates that there is no penalty for using materials with a large deflection when comparing the same topology. This result is unrealistic for most real life situations where the deflection must be kept below a definitive value. An arbitrary deflection criteria of $1 \%$ of the length of the plate has therefore been introduced for the limit state, while this value is more realistic it is still an arbitrary value that would require selection on a product by product basis. The introduction of the WWFE criteria allowed a much more realistic analysis of the plate generating probabilities of failure closer to those expected in a real life scenario. The resulting plates showed that the e-glass/vinylester plate was 50 times more likely to fail than that of the carbon/epoxy plate due to its lower stiffness and strength characteristics.

From table 6 it can be seen that the values, mean and coefficient of variation, used are developed from work carried out previously by Shenoi et al. [51] and not from experiment. This is an area of work that will need to be improved in the future as these values provide an important part of the analysis for the structure provided. Furthermore developing research is showing the importance of investigating spatial reliability. Experimental and statistical analysis relating to the properties required to perform the World Wide Failure Exercise analysis will also be vital.

The reliability analysis, while not utilising any techniques to increase the speed of the monte carlo simulation, took $385 \mathrm{mins}$ to run $10^{8}$ scenarios on a standard desktop pc. The analysis therefore takes less than one working day to complete. This analysis is reasonably rapid in its approach allowing a high level of accuracy to assess the reliability of composite grillages. While the speed of the analysis is rapid their are inaccuracies in the grillage method. It is therefore hoped in the future that a similar analysis can be performed using finite element analysis to allow a comparison between the methods.

\section{Conclusions}

This paper has presented a rapid method for reliability analysis for composite structures using Monte Carlo simulation. The reliability method has been verified against previous studies giving results for composite materials both carbon/epoxy and e-glass/vinylester. The structural methodology has been performed using grillage theory under out of plane loading. The results show that the Monte Carlo method is working correctly and can be used to determine the reliability of different plates. The paper introduces failure criteria from the World Wide Failure Exercise and a maximum deflection criteria to evaluate the reliability of a composite grillage plate. The methodology gives a reasonably rapid assessment for the reliability of composite grillage plates. This analysis shows a large decrease in the reliability of the plate from the previous failure criteria used to the results found with the World Wide Failure Exercise Criteria and therefore shows the importance in their incorporation in future reliability analysis for composite grillages.

\section{Acknowledgments}

The research is kindly sponsored by the British Marine Federation (BMF) through the National Composites Network (NCN) and through Engineering and Physical Sciences Research Council (EPSRC).

\section{References}

[1] M. MAYER. Die sicherheit der bauwerke und ihre berechnung nach grenzkraften statt nach zulassigen spannung. Berlin:Springer-Verlag, 1926. 
[2] N.S. STRELETZKI. Statistical basis for the evaluation of the structural safety factor. Stroizdat,Moscow:State Publishing House for Buildings, 1947.

[3] W. WIERZBICKI. Safety of structures as a probabilistic problem. Technical report, Przeglad Techniczny, Warsaw, Poland, 1936.

[4] C.A. CORNELL. A probability-based structural code. ACI Journal, pages 974-985, 1969.

[5] B.N. CASSENTI. Probabilistic static failure of composite materials. AIAA Journal, vol. 22:pp. 103$110,1984$.

[6] L. YANG. Reliability of composite laminates. Mechanics of Structures and Materials, vol. 16:pp. 523-536, 1988.

[7] G. CEDERBAUM, I. ELISHAKOFF, and L. LIBRESCU. Reliability of laminated plates via the firstorder second-moment method. Composite Structures, vol. 15:pp. 161-167, 1990.

[8] D.J. THOMAS and R.C. WETHERHOLD. Reliability analysis of continuous fiber composite laminates. Composite Structures, vol. 17:pp. 277-293, 1991.

[9] D.J. THOMAS and R.C. WETHERHOLD. Reliability analysis of continuous fiber composite laminates with load sharing. Composite Structures, vol. 25:pp. 1459-1475, 1991.

[10] T.Y. KAM, S.C. LIN, and K.M. HSIAO. Reliability analysis of nonlinear laminated composite plate structures. Composite Structures, vol. 25:pp. 503-510, 1993.

[11] M.R. GURVICH and R.B. PIPES. Probabilistic analysis of multi-step failure process of a laminated composite in bending. Composite Science and Technology, vol. 55:pp. 413-421, 1995.

[12] M.R. GURVICH and R.B. PIPES. Probabilistic strength analysis of four-directional laminated composites. Composite Science and Technology, vol. 56:pp. 649-656, 1996.

[13] T.Y. KAM. Reliability formulation for composite laminates subjected to first-ply failure. Composite Structures, vol. 38:pp. 447-452, 1997.

[14] S. MAHADEVAN, X. LIU, and Q. XIAO. A probabilistic progressive failure model of composite laminates. Journal of Reinforces Plastics and Composites, vol. 16:pp. 1020-1038, 1997.

[15] L. SENTLER. Reliability of high performance fibre composites. Reliability Engineering and System Safety, vol. 56:pp.181-296, 1997.

[16] C. BOYER, A. BEAKOU, and M. LEMAIRE. Design of a composite strcutre to achieve a specified reliability level. Reliability Engineering and System Safety, vol. 56:pp.273-283, 1997.

[17] M. MIKI, Y. MUROTSU, T. TANAKA, and S. SHAO. Reliability-based optimization of fibrous laminated composites. Reliability Engineering and System Safety, vol. 56:pp.285-290, 1997.

[18] H.K. JEONG and R.A. SHENOI. Reliability analysis of mid-plane symmetric laminated plates using direct simulation method. Composite Structures, vol. 43:pp. 1-13, 1998.

[19] H.K. JEONG and R.A. SHENOI. Probabilistic strength analysis of rectangular frp plates using monte carlo simulation. Computers and Structures, vol. 76:pp. 219-235, 2000. 
[20] N-Z. CHEN and C. SUN, H-H.and GUEDES SOARES. Reliability analysis of a ship hill in composite materials. Composites Structures, vol. 62:pp.59-66, 2003.

[21] N-Z. CHEN and C.. GUEDES SOARES. Reliability assessment for ultimate longitudinal strength of ship hulls in composite materials. Probabilistic Engineering Mechanics, vol. 22:pp.330-342, 2007.

[22] C.C. ANTONIO and L.N. HOFFBAUER. Uncertainty analysis on sensitivity applied to angle-ply composite structures. Reliability Engineering and System Safety, vol. 92:pp.1353-1362, 2007.

[23] E. CASTILLO, R. MINGUEZ, and C. CASTILLO. Sensitivity analysis in optimization and reliability problems. Reliability Engineering and System Safety, vol. 93:pp.1788-1800, 2008.

[24] M.B. WHITESIDE, S.T. PINHO, and P. ROBINSON. Stochastic failure modelling of unidirectional composite ply failure. Reliability Engineering and System Safety, In Press, 2012.

[25] C.D. EAMON and M. RAIS-ROHANI. Integrated reliability and sizing optimization of a large composite structure. Marine Structures, vol. 22:pp.315-334, 2009.

[26] L.S. SUTHERLAND and C. GUEDES SOARES. Review of probabilistic model of the strength of composite materials. Reliability Engineering and System Safety, vol. 56:pp.183-196, 1997.

[27] C. GUESDES SOARES. Reliability of components in composite materials. Reliability Engineering and System Safety, vol. 55:pp.171-177, 1997.

[28] M. CHIACHIO, J. CHIACHIO, and G. RUS. Reliability in composites - a selective review and survey of current developments. Composites Part: B, vol. 24:pp.902-913, 2012.

[29] J.I.R. BLAKE, R.A. SHENOI, O. DAS, and N. YANG. The application of reliability methods in the design of stiffened frp composite panels for marine vessels. Ship and Offshore Structures, vol. 4(2):pp.287-297, 2009.

[30] G. VEDELER. Grillage Beams. Grondahl and son, 1945.

[31] K. MANEEPAN, J.I.R. SHENOI, and J.I.R. BLAKE. Genetic algorithms (gas) based optimisation of frp composite plated grillages in ship structures. Transactions of The Royal Institution of Naval Architects Part A: International Journal of Maritime Engineering, vol. 149:1-19, 2007.

[32] M.H. DATOO. Mechanics of Fibrous Composites. Elsevier Science Publishers Ltd., Essex, England, 1991.

[33] A.J. SOBEY, J.I.R. BLAKE, and R.A. SHENOI. Optimization of composite boat hull structures. In Computer and Information Management Applications for Shipbuilding (COMPIT),Liege, pages pp.502-515, 2008.

[34] A.S. KADDOUR, M.J. HINTON, and P.D. SODEN. A comparison of the predictive capabilities of current failure theories for composite laminates: additional contributions. Composites Science and Technology, vol. 64:pp.449-476, 2004.

[35] M.J. HINTON, A.S. KADDOUR, and P.D. SODEN. Evaluation of failure prediction in composite laminates: background to 'part b' of the exercise. Composites Science and Technology, vol. 62:pp.14811488, 2002. 
[36] M.J. HINTON, A.S. KADDOUR, and P.D. SODEN. Evaluation of failure prediction in composite laminates: background to 'part c' of the exercise. Composites Science and Technology, vol. 64:pp.321$327,2004$.

[37] P.D. SODEN, A.S. KADDOUR, and M.J. HINTON. Recommendations for designers and researchers resulting from the world-wide failure exercise. Composites Science and Technology, vol. 64:pp.589604, 2004.

[38] A. PUCK and H. SCHURMANN. Failure analysis of frp laminates by means of physically based phenomenological models. Composites Science and Technology, vol. 58:pp.1045-1067, 1998.

[39] A. PUCK and H. SCHURMANN. Failure analysis of frp laminates by means of physically based phenomenological models. Composites Science and Technology, vol. 62:pp.1633-1662, 2002.

[40] K. LIU and S.W. TSAI. A progressive quadratic failure criterion for a laminate. Composites Science and Technology, vol. 58:pp.1023-1032, 1998.

[41] A. KURAISHI, S.W. TSAI, and K.K.S. LIU. A progressive quadratic failure criterion, part b. Composites Science and Technology, vol. 62:pp.1683-1695, 2002.

[42] P.A. ZINOVIEV, S.V. GRIGORVIEV, O.V. LEBEDEVAB, and L.P. TAIROVA. The strength of multilayered composites under a plane-stress state. Composites Science and Technology, vol. 58, 1998.

[43] P.A. ZINOVIEV, O.V. LEBEDEVA, and L.P. TAIROVA. A coupled analysis of experimental and theoretical results on the deformation and failure of composite laminates under a state of plane stress. Composites Science and Technology, vol. 62:pp.1711-1723, 2002.

[44] A.S. NOWAK and K.R. COLLINS. Reliability of Structures. McGraw-Hill Higher Education, 2000.

[45] J.I.R. BLAKE, P. DAS, A.K. NAYAK, and R.A. SHENOI. Stochastic analysis of stiffened panels. Technical report, University of Southampton, University of Glasgow and Strathclyde, 2008.

[46] J.M.C. CADAI, T.J. STRATFORD, L.C. HOLLAWAY, and W.G. DUCKETT. Strengthening metallic structures using externally bonded fibre-reinforced polymers. Classic House, 2004.

[47] DNV. Design of offshore steel structures load and resistance factor design method. Technical Report OSC101, Oslo, 2000.

[48] Report of a Concrete Society Committee. Design guidance for strengthening concrete structures using fibre composite materials. Technical Report No. 55, The Concrete Society, 2004.

[49] R.Y. RUBINSTEIN and D.P. KROESE. Simulation and the Monte Carlo Method. Wiley, 2008.

[50] J. CLARKSON. The elastic analysis of flat grillages. Cambridge University Press, 1965.

[51] R.A. SHENOI, P. DAS, A.K. NAYAK, and J.I.R. BLAKE. Safe design of a composite structure - a stochastic approach. Technical report, University of Southampton University of Glasgow and Strathclyde, 2006.

[52] DNV offshore standard. Composite components. Technical Report DNV-OS-C501, DET NORSKE VERITAS, 2003.

[53] COMMITTEE IV.1. Design principles and criteria. In Proceedings of the 13th International Ship and Offshore Structures Congress, Trondheim, Norway, 1997. 